Article

\title{
Temporal-Spatial Differentiation and Optimization Analysis of Cultivated Land Green Utilization Efficiency in China
}

\author{
Qianru Chen and Hualin Xie * \\ Institute of Ecological Civilization, Jiangxi University of Finance and Economics, Nanchang 330013, China; \\ cqrjufe@163.com \\ * Correspondence: xiehl_2000@163.com; Tel.: +86-791-8397-9115
}

Received: 11 October 2019; Accepted: 21 October 2019; Published: 24 October 2019

\begin{abstract}
Cultivated land is closely related to national food security, rural economic development and social stability. The cultivated land pollution and carbon emissions caused by chemical fertilizers, pesticides, film residues, etc., in the process of cultivated land utilization pose a serious threat to the cultivated land ecosystem in China. The comprehensive analysis on the cultivated land green utilization efficiency (GUECL), its influencing factors, and optimization direction provides a valuable basis for the green utilization of cultivated land. Based on a panel data of 30 provinces (cities or districts) in China from 2001 to 2016, the GUECL in China under the constraints of pollution and carbon emissions was measured by using a super-efficient SBM-VRS (slack based model-variable return to scale) model. The influencing factors and optimization directions of the GUECL were analyzed through the Tobit model and slack values, respectively. The results show that the GUECL in China rose with fluctuations from 2001 to 2016. Since 2014, the eastern region has surpassed the western region and has become the region with the highest mean GUECL value. The room for resource conservation and pollution reduction varies in different regions of China. Farmers' dependence on cultivated land and agricultural added value are positively related to the GUECL in China. Farmers' occupational differentiation, agricultural machinery density, and agricultural disaster rate have had negative effects on the GUECL in China. The loss of the GUECL in China is mainly due to the redundancies of land input, pollution emission, and mechanical input. By analyzing these influencing factors and optimization directions, it is concluded that improving rural land transfer market and agricultural infrastructure construction, establishing a new agricultural technology extension system, and vigorously cultivating new professional farmers are the targeted measures to improve the GUECL.
\end{abstract}

Keywords: green utilization efficiency of cultivated land (GUECL); super-efficiency SBM-VRS model; optimization direction; influencing factors

\section{Introduction}

Cultivated land is the uppermost agricultural productive material. In the period of 2004-2015, China achieved "twelve consecutive increases" in grain production, with an average annual growth rate of $2.8 \%$. However, the high grain yield was at the high expense of cultivated land pollution and soil fertility overdraft. Research has shown that the increase in cultivated land output mainly depended on the increase in chemical fertilizer application [1]. During 1965-1993, the increased application of chemical fertilizer contributed to $21.7 \%-40 \%$ of the increase in agricultural output [2]. However, with an effective utilization rate of $35 \%$, about $65 \%$ of the applied chemical fertilizer remained in the soil and resulted in agricultural non-point source pollution [3], posing a threat to soil safety, food safety 
and grain security. According to the Chinese National Bulletin of Soil Pollution Survey (2014), the over standard rate of soil sites in cultivated land was $19.1 \%$, of which $13.2 \%, 2.8 \%, 1.8 \%$ and $1.1 \%$ were slightly, mildly, moderately and severely polluted, respectively, suggesting the concentrated and frequent occurrence of heavy metal pollution in China. Studies show that agricultural $\mathrm{CO}_{2}$ emission accounts for $21 \%-25 \%$ of the total anthropogenic greenhouse gas emissions. It has become one of the important sources of greenhouse gas emissions [4]. According to the 2016 Chinese Land Resource Bulletin, China saw a net decrease of 43.5 thousand hectares of cultivated land in 2016. According to the Chinese Environmental Status Bulletin 2015, top-grade cultivated land area in China only accounted for $2.9 \%$ of the country's total appraised cultivated land area in 2014; high-grade, medium-grade, and low-grade cultivated land accounted for $26.5 \%, 52.9 \%$, and $17.7 \%$, respectively. These percentages show that the ecology of cultivated land in China is relatively weak [5]. The increased polluted area of high-quality cultivated land, aggravated potential polluted area, deteriorated regional ecology, and disappearing high-quality cultivated land resources indicate that the overall cultivated land quality in China is declining, and cultivated land development and utilization are nearing the ecological limit [6].

As a basic resource, cultivated land ensures the normal survival and development of human society. It is the fundamental guarantee of national food security and social stability. According to Pawar and Gatade, land utilization efficiency determines agricultural productivity [7]. Under the tightening constraints of cultivated land resources and environmental carrying capacity, the assessment of the cultivated land green utilization efficiency (GUECL) contributes to coordinate the relationship between cultivated land production and the ecological environment; it is of great significance for agricultural sustainable development and national food security. Xie et al. (2018) defined "the optimal green utilization efficiency of cultivated land" as "the maximum economic and ecological benefit that can be achieved under the constraints of certain economic and environmental costs during the process of cultivated land utilization" [8]. In the assessment of the GUECL, the ignorance of the negative impacts of pesticides, fertilizers and carbon emissions on the ecological environment inevitably result in an imperfect land utilization efficiency index system and a distorted reflection of the actual situation. Along these lines, this paper comprehensively evaluated the GUECL under the constraints of pollution and carbon emissions, aiming to solve the following problems:

(1) What is the GUECL in China? What characteristics of temporal and spatial differentiation does it present?

(2) What are the influencing factors of the GUECL in China? What measures can be taken to improve the GUECL in China?

(3) In terms of the input and output of cultivated land utilization, from what directions can we optimize the green utilization efficiency of cultivated land in China?

\section{Literature Review}

In recent years, studies on cultivated land utilization efficiency have been gradually enriched, mainly focusing on measuring cultivated land utilization efficiency and analyzing influencing factors redundancy rates, etc. As the agricultural ecological environment deteriorates and the carrying capacity of environmental resources aggravates, the cultivated land utilization efficiency can be overestimated without considering the undesirable output. Thus, in later studies, the "undesirable

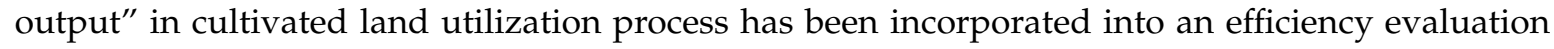
framework under the constraints of resource and environment. In this way, the evaluation objects are expanded, including agricultural environmental efficiency [9], ecological environmental efficiency [10] and agricultural green production efficiency [11]. For example, Lu et al. (2018) took carbon emissions as the undesirable output, and they found that a cultivated land use efficiency value formed after considering the carbon emissions decreased by a different extent than that without considering carbon emissions [12]. With the deepening of research, studies on cultivated land utilization efficiency from different perspectives and scales have been gradually enriched. On the plot scale, Catherine found that the investment of irrigation and water conservancy facilities was one of the main factors that 
affects cultivated land utilization efficiency [13]. Rahma and Rahman found that land fragmentation significantly decreases technical production efficiency [14]. Oumarou et al. found that farm size plays a significant role in improving the technical efficiency of rice production [15]. In Manjunatha et al.'s study on the impact of farm size on resource utilization efficiency, it was found that smaller farms have a higher resource utilization efficiency while land fragmentation in larger farms results in resource waste [16]. On the farmer scale, many studies have shown that farmers' age [17], farmers' education level [18], farmers' training time [19] and agricultural population [20] are important factors that influence the efficiency of cultivated land utilization. Furthermore, in addition to the direct factors which affect cultivated land utilization efficiency, the indirect factors which affect cultivated land utilization efficiency, such as farmland right confirmation and cultivated land circulation, have also begun to attract scholars' attention.

Efficiency evaluation methods based on the production frontier include the parametric method (e.g., the stochastic frontier method, SFA) and the non-parametric method. The non-parametric method does not require the presetting of the functional relationship when evaluating efficiency, thus greatly avoiding subjective controversy in the evaluation process, especially for macro-evaluation with multi inputs and outputs. Data envelopment analysis (DEA) is the most commonly used non-parametric frontier efficiency analysis method [21]. DEA was first proposed in an American study by Charnel et al. (1978), and, after a series of extensions, dozens of models have now been formed [22]. Chung et al. (1997) proposed the directional distance function (DDF), which is a model based on DEA [23]. DDF aims to increase desirable outputs while reducing inputs or undesirable outputs by giving the corresponding direction vector in advance. The DDF assumes that inputs and outputs vary in the same proportion. However, if nonzero slack variables exist, the efficiency value might be overestimated. Therefore, some scholars have proposed the non-radial DDF, with which they calculate directional slack variables [24-28]. Based on the non-radial direction distance function, the slack-based model (SBM) directly adds slack variables into the objective function; therefore, the economic aim of the SBM is to maximize the actual profit rather than the benefit ratio [29]. The SBM is more in accordance with the actual production situation. Despite many improvements to the models, a common defect exists in all the above models. The efficiency values obtained by using the above method are distributed between $(0,1]$.

The efficiency values of the effective decision-making units (DMUs) are all 1, so multiple effective DMUs cannot be further compared. Tone (2002) proposed the super-efficient SBM model to make up for the inability to calculate the efficient DMUs' efficiency values [30]. First, the SBM model was used to evaluate all DMUs, and then the super-efficiency SBM model was used to further evaluate the SBM-effective DMUs. Therefore, to ensure that the evaluation results are more consistent with the actual situation, the super efficiency SBM-VRS (slack based model-variable return to scale), which is based on undesirable outputs, is adopted to evaluate the GUECL in China. The efficiency value obtained by the super efficiency SBM-VRS model is a truncated variable greater than 0 , which should be estimated through the Tobit model. Therefore, the DEA-based non-parametric analysis method and the Tobit model are usually combined to make the DEA two-stage method [31,32].

Through a literature review, it was found that although studies on cultivated land utilization efficiency are more and more abundant, some limits still exist: First, some factors have not been taken into consideration in the selection of input or output indicators, especially the undesirable output indicators. For example, some important sources of carbon emissions have not been taken into consideration, or only the agricultural non-point source pollution has been considered as the undesirable output, resulting in the over-evaluation of efficiency values. Second, the maximum efficiency values obtained by present evaluation methods have mostly been 1 , making it difficult to further compare the effective DMUs. Based on these limitations and the provincial panel data from 2001-2016 in China, this paper integrates the loss of nitrogen and phosphorus from fertilizer, pesticide loss, and agricultural film residue as a cultivated land pollution emissions index using the entropy weight method, and we calculate the carbon emissions caused by carbon sources of fertilizer, pesticide, 
film, agricultural diesel oil, irrigation, tilling, and machinery using carbon emission coefficients. Then, the GUECL in China is evaluated through the SBM-VRS model under the dual constraints of agricultural pollution and carbon emissions. At last, based on the Tobit model and a slack analysis, the influencing factors and optimization directions of the GUECL are analyzed to provide references for cultivated land protection and policy formulation.

\section{Model Construction and Index Selection}

\subsection{Super-Efficiency SBM-VRS Model}

Based on Tone's theoretical premise on the non-radial and non-angular SBM model, the super-efficiency SBM-VRS model is set as follows:

Assuming that there are $n$ DMUs, the inputs, desirable outputs, and undesirable outputs of each DMU are represented by $m, r_{1}$ and $r_{2}$, respectively, as well as by vectors as $x \in R^{m}, y^{d} \in R^{r_{1}}, y^{u} \in R^{r_{2}}$. $X, Y^{d}$ and $Y^{u}$ represent matrixes $X=\left[x_{1} \cdots x_{n}\right] \in R^{m \times n}, Y^{d}=\left[y_{1}^{d} \cdots y_{n}^{d}\right] \in R^{r_{1} \times n}$ and $Y^{u}=\left[y_{1}^{u} \cdots y_{n}^{u}\right] \in$ $R^{r_{2} \times n}$, respectively. $\mathrm{K}$ denotes the provinces (autonomous regions or municipalities directly under the central government). The super-efficiency SBM-VRS model is developed as follows:

$$
\begin{gathered}
\min \varphi=\frac{1 / m \sum_{i=1}^{m}\left(\bar{x} / x_{i k}\right)}{1 /\left(r_{1}+r_{2}\right)\left(\sum_{s=1}^{r_{1}} \overline{y^{d}} / y_{s k}^{d}+\sum_{q=1}^{r_{2}} \overline{y^{u}} / y_{q k}^{u}\right)} \\
\bar{x} \geq \sum_{j=1, \neq k}^{n} x_{i j} \lambda_{\mathrm{j}} \quad i=1, \cdots, \mathrm{m} \\
\overline{\mathrm{y}^{\mathrm{d}}} \leq \sum_{j=1, \neq k}^{n} \mathrm{y}_{\mathrm{sj}}^{\mathrm{d}} \lambda_{\mathrm{j}} \quad \mathrm{s}=1, \cdots, \mathrm{r}_{1} \\
\text { s.t. } \quad \overline{\mathrm{y}^{\mathrm{d}}} \geq \sum_{j=1, \neq k}^{n} \mathrm{y}_{\mathrm{qj}}^{\mathrm{b}} \lambda_{\mathrm{j}} \quad \mathrm{q}=1, \cdots, \mathrm{r}_{2} \\
\lambda_{\mathrm{j}}>0 \quad j=1, \cdots, n \quad j \neq 0 \\
\bar{x} \geq x_{k} \quad s=1, \cdots, r_{1} \\
\bar{y}^{u} \geq y_{k}^{u} \quad q=1, \cdots, r_{2}
\end{gathered}
$$

\subsection{The Input and Output Indicators of the GUECL}

The evaluating indicators are classified into two categories according to the DEA method: input indicators and output indicators. Referring to the existing research, in view of the availability of research data, the input and output indicators of this paper are selected as follows (Table 1): 
Table 1. The input and output indicators for the cultivated land green utilization efficiency (GUECL) evaluation.

\begin{tabular}{|c|c|c|}
\hline Primary Indices & Secondary Indices & Variables and Descriptions \\
\hline \multirow[b]{3}{*}{ Inputs } & Agricultural labor input & $\begin{array}{c}\text { AFAHF } \times(\text { Total agricultural output/TO) (ten thousand } \\
\text { people })\end{array}$ \\
\hline & Agricultural land input & Total sown area of crops (thousand hectare) \\
\hline & Agricultural capital input & $\begin{array}{c}\text { OVPFA (Yuan/per person) } \\
\text { Consumption of chemical fertilizers (ten thousand tons) } \\
\text { Consumption of pesticide (ten thousand tons) } \\
\text { Consumption of agricultural film (ten thousand tons) } \\
\text { Total agricultural machinery power (ten thousand kw) } \\
\text { Effective irrigation area (thousand hectares) }\end{array}$ \\
\hline $\begin{array}{l}\text { Desirable } \\
\text { Outputs }\end{array}$ & Total agricultural output & Total agricultural output (ten thousand Yuan) \\
\hline \multirow{2}{*}{$\begin{array}{l}\text { Undesirable } \\
\text { Outputs }\end{array}$} & Pollution emission & $\begin{array}{l}\text { agricultural pollution emission index integrated from the } \\
\text { loss of nitrogen and phosphorus from fertilizer (ten } \\
\text { thousand tons), pesticide loss (ten thousand tons), and } \\
\text { agricultural film residuals (ten thousand tons) }{ }^{1}\end{array}$ \\
\hline & Carbon emission & $\begin{array}{l}\text { The total carbon emissions of chemical fertilizer, } \\
\text { pesticide, agricultural film, agricultural diesel oil, } \\
\text { agricultural irrigation, agricultural tilling and } \\
\text { agricultural machinery (ten thousand tons) }\end{array}$ \\
\hline
\end{tabular}

Note: AFAHF is short for people engaged in agriculture, forestry, animal husbandry and fishery; TO is short for total output value of agriculture, forestry, animal husbandry and fishery; OVPFA is short for the original value of productive fixed assets of rural households at the end of the year. ${ }^{1}$ The cultivated land pollution emission index is calculated by entropy weight method.

Land, labor force, and capital are the three basic production factors of cultivated land production. (1) Labor input: As the labor input data of crop production is unavailable, this indicator is replaced through multiplying AFAHF with the ratio of total agricultural output to total output (TO) (found by referring to Feng et al.'s (2015) study [33]). (2) Land input: Considering multiple cropping and inter-planting in cultivated land production, land input is represented by crop sown area. (3) Capital input: The original value of productive fixed assets of rural households at the end of the year (OVPFA) refers to the value of draft animals, large and medium-sized iron and wood agricultural tools, agricultural machinery, vehicle and production housing, etc., thus covering the monetary value of the main capital inputs in the process of cultivated land utilization. Total agricultural machinery power reflects the status of energy utilization in agricultural production. The large input of production means that things such as chemical fertilizer and pesticide are the typical characters of the intensive utilization of cultivated land. In this paper, the inputs of chemical fertilizer, pesticide and agricultural film are represented by their actual consumption amount. Irrigation input is represented by the effective agricultural irrigation area.

In the actual process of cultivated land utilization, the output is considered as the multiple products produced by multiple inputs, so a comprehensive index should be adopted to measure complex change in regard to the calculation of total output [1]. In this paper, total agricultural output was selected as the desirable output indicator of the GUECL. The undesirable outputs include carbon and pollution emissions. In this paper, chemical fertilizers, pesticides, agricultural film, agricultural diesel oil, agricultural irrigation, agricultural tilling, and agricultural machinery were selected as the carbon emission sources of cultivated land. The above indexes were multiplied by the corresponding carbon emission coefficients, and the total carbon emission of cultivated land was obtained. The calculating formula is as follows:

$$
E=\sum_{i=1}^{7} E_{i}=\sum_{i=1}^{7} T_{i} \tau_{i}
$$


In the above Equation, $E$ is the total carbon emission, $E_{i}$ is the carbon emission of each carbon source, $\tau_{i}$ is the carbon emission coefficient of each carbon source ${ }^{1}$, and $T_{i}$ is the original amount of each carbon emission source.

The pollution emissions in cultivated land utilization mainly originate from nitrogen and phosphorus loss in fertilizer (ten thousand tons), pesticide loss (ten thousand tons) and agricultural film residue (ten thousand tons). According to relevant studies, the pesticide loss rate was about $50 \%$ [34], the film residue rate was about $10 \%$ [35], and the coefficient of nitrogen and phosphorus loss in fertilizer was obtained according to Lai et al.'s (2004) unit analysis method ${ }^{2}$ [36]. Using the entropy weight method, nitrogen and phosphorus loss in chemical fertilizer, as well as pesticide loss and agricultural film residue are integrated as the cultivated land pollution emission index.

\section{Analysis on the Temporal-Spatial Differentiation of the GUECL}

\subsection{The Overall Evaluation of the GUECL}

Based on input, desirable output, and undesirable output data, using the MaxDEA 7.0 software as the computing platform, the GUECL value from 2001 to 2016 in China was measured using the super-efficiency SBM-VRS model. The GUECL value for China was the geometric mean of the GUECL values in different provinces. The results are shown in Figure 1.

In general: (1) The GUECL in China showed a rising trend with fluctuations during 2001-2016; (2) the average value of the GUECL in China was 0.52 from 2011 to 2016, indicating that the overall level of the GUECL in China was relatively low and there was still much room for resource conservation and environmental protection in cultivated land utilization. The GUECL value in each region was the geometric mean of the GUECL values of the provinces within the region. From 2001 to 2010, the GUECL values of the three regions were ranked as follows: west > east > central. The GUECL in eastern China began to catch up from 2011 and surpassed that of the western region from 2014, ranking first. After 2014, the GUECL values of the three regions were ranked as follows: east > west > central.

Combining Tu's (2008) classification method for environmental technical efficiency with this study [37], the regions with efficiency values between $[1,+\infty),(0.9,1),(0.8,0.9],(0.7,0.8],(0.6,0.7]$ and $(0,0.6]$ were defined, respectively, as efficient groups, high-efficiency groups, relatively high-efficiency groups, medium-efficiency groups, relatively low-efficiency groups, and low-efficiency groups. During 2001-2016, the 31 provinces in China were, to varying extents, in a state of ineffective green utilization of cultivated land. In terms of the mean value of the GUECL during 2001-2016, only Qinghai (0.98) and Shanghai (0.91) belonged to high-efficiency groups. There were 22 provinces, accounting for $73 \%$ of the provinces, belonging to low-efficiency groups with a GUECL value lower than 0.6. This indicates that there is still much room for resource conservation and pollution control in the inputs and outputs of cultivated land utilization (Figure 2).

1 The carbon emission coefficients of chemical fertilizer (West and Marland, 2002), pesticide (Post and Kwon, 2000), agricultural film (Li et al., 2011), agricultural diesel oil (Wang et al., 2018), agricultural irrigation (Li et al., 2011), agricultural tilling (Wu et al., 2007), and agricultural machinery (West and Marland, 2002) were $0.896 \mathrm{~kg} / \mathrm{kg}, 4.934 \mathrm{~kg} / \mathrm{kg}, 5.180 \mathrm{~kg} / \mathrm{kg}, 0.593 \mathrm{~kg} / \mathrm{kg}$, $20.476 \mathrm{~kg} / \mathrm{hm}, 312.6 \mathrm{~kg} / \mathrm{hm}$, and $0.18 \mathrm{~kg} / \mathrm{kw}$, respectively.

2 According to Lai et al.'s (2004) unit analysis method, the nitrogen loss rate and phosphorus loss rate from chemical fertilizer in Jiangsu and Beijing were $30 \%$ and $7 \%$, respectively; the nitrogen loss rate and phosphorus loss rate in Tianjin, Guangdong, Zhejiang and Shanghai were $30 \%$ and $4 \%$, respectively; the loss rates in Hubei, Fujian and Shandong were $20 \%$ and $7 \%$, respectively; the loss rates in Hebei, Shaanxi, Liaoning, Yunnan, Ningxia, Hunan, Jilin, Inner Mongolia and Guizhou were $20 \%$ and $4 \%$, respectively; the loss rates in Henan and Heilongjiang were $10 \%$ and $7 \%$, respectively; the loss rates in Anhui, Hainan, Xinjiang, Shanxi, Guangxi, Gansu, Sichuan, Jiangxi, Chongqing, Qinghai and Xizang were 10\% and 4\%, respectively. 


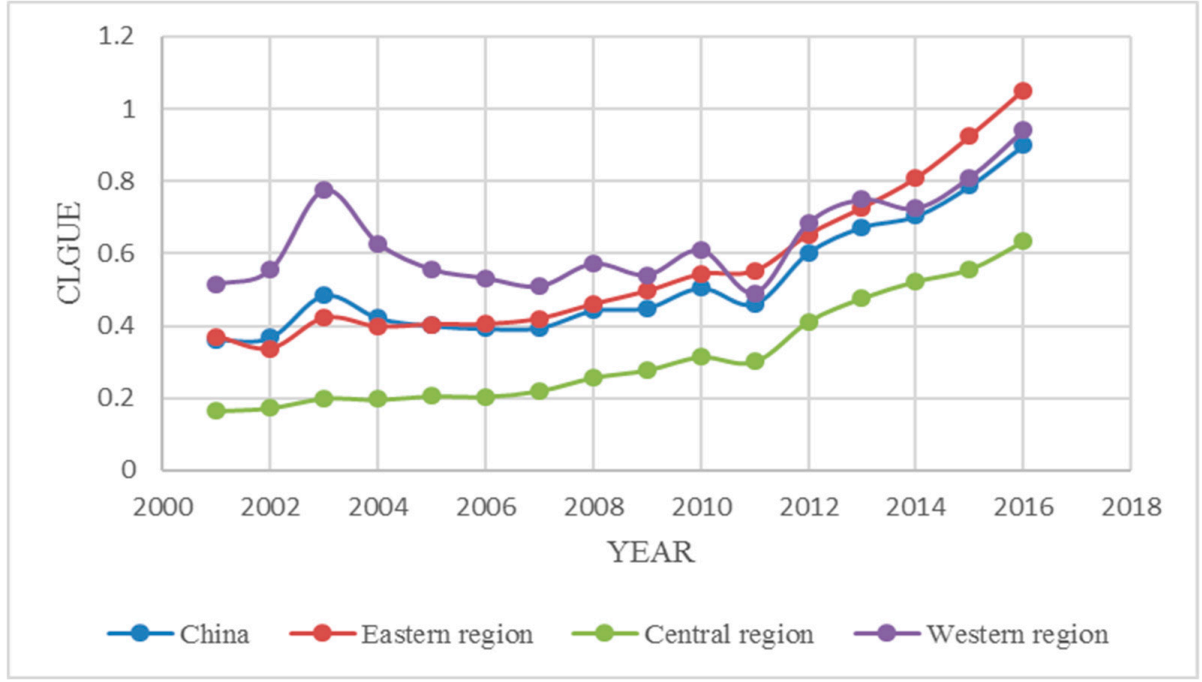

Figure 1. The GUECL fluctuating trends in eastern, middle, western and the whole of China. Note: Data in this paper were sourced from the China Statistical Yearbook, China Rural Statistical Yearbook and China Demographic Statistical Yearbook from 2001 to 2016. To eliminate the influence of price factors, the total agricultural output value was converted into the constant 2001 price. As the data on OVPFA from 2013-2016 were unavailable, the data on OVPFA from 2013-2016 were calculated using the following formula: OVPFA $A_{t}=\frac{R H F A I_{t}}{R_{H F A I_{212}}} \cdot \mathrm{OVPFA} A_{2012}$. In the above formula, RHFAIt represents the value of rural household fixed asset investment in the $t$-th year, which is between 2013 and 2016 in the paper. Due to the incomplete data on effective irrigation area in certain years during 2014-2016, in order to maintain data consistency, the incomplete data were calculated based on the annual average growth rate from 2001 to the previous year.

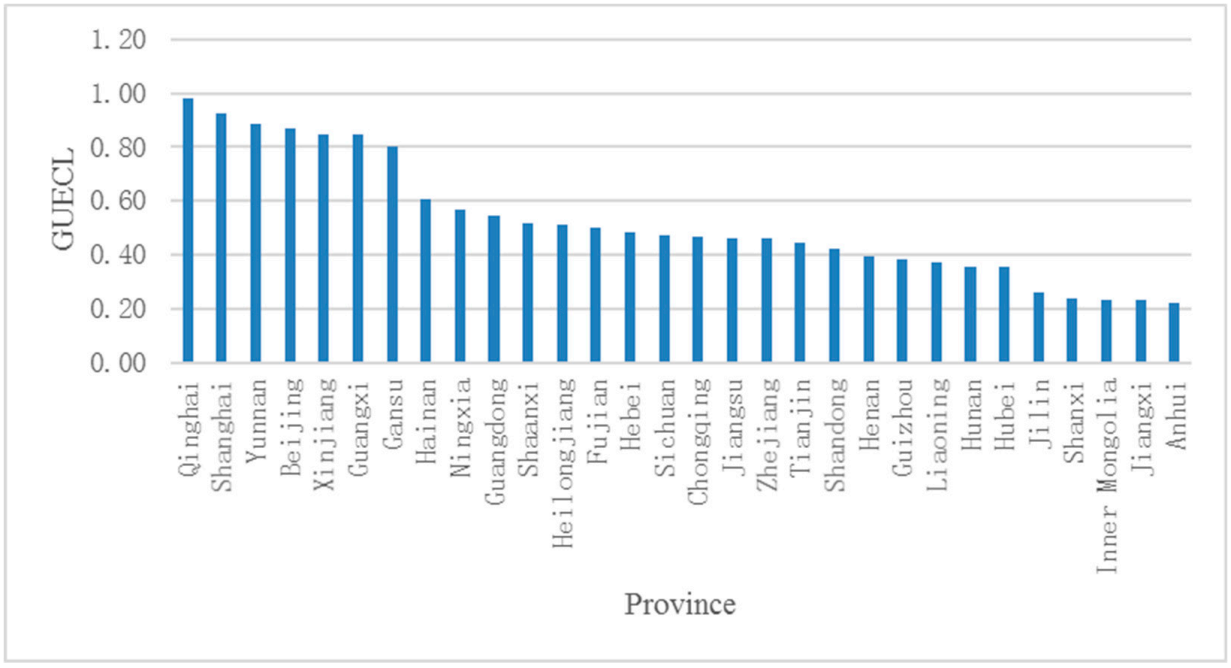

Figure 2. The mean GUECL in 30 provinces in China from 2001-2016. Note: According to the economic development level, this paper classifies China's 31 provinces into three regions: the eastern, central and western regions. The eastern region includes Beijing, Tianjin, Hebei, Liaoning, Shanghai, Jiangsu, Zhejiang, Fujian, Shandong, Guangdong and Hainan. The central region includes Shanxi, Jilin, Heilongjiang, Anhui, Jiangxi, Henan, Hubei, and Hunan. The western region includes Sichuan, Chongqing, Guizhou, Yunnan, Shaanxi, Gansu, Qinghai, Ningxia, Xinjiang, Guangxi, and Inner Mongolia. Due to its special natural and geographical conditions, Tibet is not included in this study. Limited by data, Hong Kong, Taiwan and Macao are not included in this study. 


\subsection{Temporal-Spatial Differentiation of the GUECL}

The temporal-spatial differentiation characteristics of the GUECL in 30 provinces (autonomous regions or municipalities directly under the central government) are shown in Figure 3. Overall, from 2001 to 2011, most provinces belonged to low-efficiency groups ${ }^{3}$. Only a few provinces were scattered in other efficiency intervals. From 2011, the GUECL in most provinces increased rapidly, and there were 11 and 12 provinces achieving GUECL-efficiency in 2011 and 2016, respectively. Limited by the article space, this paper only lists the efficiency distribution of each province in 2001, 2006, 2011 and 2016 in a five-year interval. Details are as follows:
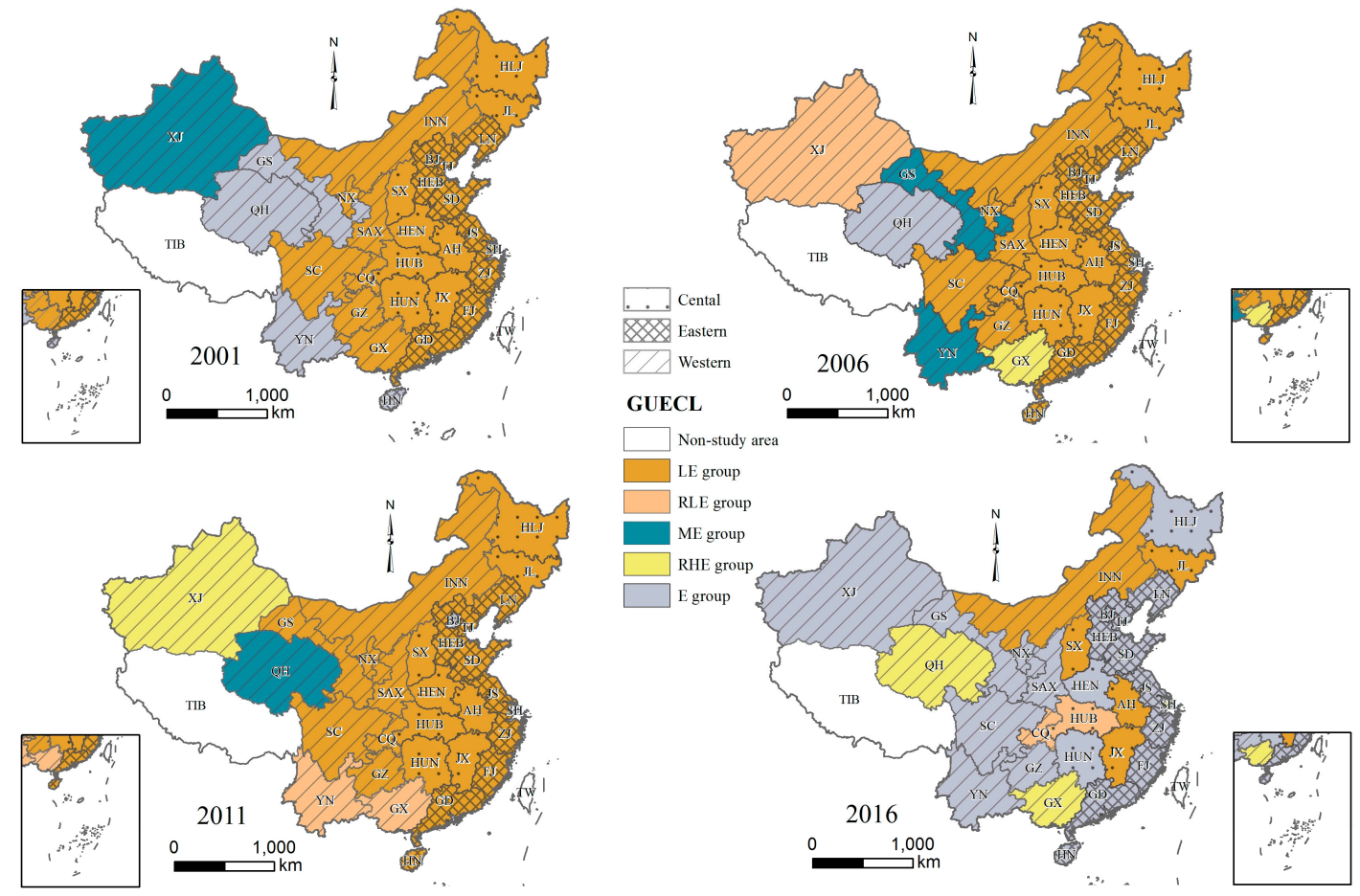

Figure 3. Temporal-spatial GUECL distribution in China. Note: The LE group, the RLE group, the ME group, the RHE group, the HE group, the E group represent the low-efficiency group, the relatively low-efficiency group, the medium-efficiency group, the relatively high-efficiency group, the high-efficiency group, and the efficient group, respectively. No province belongs to high-efficiency group in the four years.

In terms of low-efficiency groups, in 2001 , there were about $90.9 \%, 63.6 \%$, and $100 \%$ provinces in eastern, western, and central China which belonged to low-efficiency groups, respectively. In 2006, there were about $90.9 \%, 54.5 \%$, and $100 \%$ provinces in eastern, western, and central China which belonged to low-efficiency groups, respectively. Compared with 2001, only the low-efficiency provinces in the western region decreased. In 2011, there were about $81.8 \%, 63.6 \%$, and $100 \%$ provinces in eastern, western, and central China which belonged to low-efficiency groups, respectively. Compared with those in 2006, the proportions of provinces belonging to low-efficiency groups decreased in the eastern region and increased in the western region. All the provinces in the central region belonged to the low-efficiency group from 20001 to 2011, indicating that the central region was in urgent need of adjusting the cultivated land utilization mode. In 2016, only $9 \%$ provinces in the western region belonged to the low-efficiency group, and no eastern provinces were low-efficiency any more. In the

3 The classification method for efficiency groups is the same as that in Section 4.1. 
central region, there were still 50\% low-efficiency provinces. It can be concluded that no matter the GUECL level or improved efficiency, the central region lagged behind the eastern and western regions.

As shown in Figure 3, during 2001-2016, the quantity of provinces distributed between the relatively low efficiency level and the high efficiency level was small, so this paper combined these for the analysis. There were one, four, four, and two provinces at this efficiency level in 2001, 2006, 2011 and 2016, respectively. It is noteworthy that Yunnan, Gansu and Qinghai in the western region were high-efficiency in 2001, but they were medium-efficiency, low efficiency and relatively low-efficiency, respectively, in 2006 and 2011. This indicates the unstable GUECL level in the three provinces, and corresponding supporting measures should be taken to ensure the long-term and stable green utilization of cultivated land. Inconsistent with the overall GUECL evolving trend in China, the GUECL of the rest of the provinces belonging to these efficiency levels showed an upward trend in general.

In terms of effective groups, in 2001, there were only four effective provinces (accounting for about $13 \%$ of provinces in China), of which three were in the western region. This indicated that the cultivated land in $87 \%$ of provinces in China was, to varying extents, in a state of ineffective green utilization. In 2006 and 2001, the effective provinces decreased further, and there were only two effective provinces in these two years, respectively. In 2016, a total of 23 provinces, accounting for about $77 \%$, belonged to effective groups, among which $100 \%, 81.82 \%$, and $37.5 \%$ provinces of the eastern, western and central regions were effective, respectively. Compared with eastern and western regions, the GUECL in the central region was relatively low.

In terms of efficiency level, most provinces in China were low-efficiency during 2001-2011. However, in 2016, the overall GUECL level in China increased greatly with over $75 \%$ of provinces being efficient. In terms of spatial distribution, the GUECL in China during 2001-2010 was ranked as follows: western > eastern > central. Since 2001, the GUECL in the eastern region has showed a catching-up trend with the highest mean GUECL, surpassing the western region. For the central region, no matter the efficiency level or improved speed, it lags behind the eastern and western region.

\section{Analysis of the Factors Influencing the GUECL}

The GUECL measured by the super-efficiency SBM-VRS model was a truncated variable with a value range greater than 0 . For such limited dependent variables, if the OLS (ordinary least squares) method is used to estimate the model, the parameters obtained would then be inconsistent and biased, but the inconsistency and bias could be avoided by adopting the Tobit model. The Tobit regression model is an econometric model first put forward by economist James Tobin (1958) to study durable goods [38]; it was then continuously developed and improved by many economists. The Tobit model can be used to analyze factors influencing efficiency and to determine directions and ways to improve efficiency [39]. In regard to panel data, it is usually difficult to obtain consistent and unbiased estimators by adopting the fixed-effect Tobit model [40], so the random-effect panel Tobit model was adopted in this paper. The model is as follows:

$$
C L G U E_{i t}=\alpha+\sum \beta_{j} X_{j, i t}+\mu_{i}+\varepsilon_{i t}
$$

In the above formula, GUECL $L_{i t}$ represents the GUECL, $i$ and $t$ represent the $i$-th province and the $t$-th year, $\alpha$ represents the intercept term, $\beta_{j}$ represents the estimated coefficient of the $j$-th influencing factor, $X_{j, i t}$ represents the influencing factor, $\mu_{i}$ represents the individual effect, and $\varepsilon_{i t}$ represents the stochastic error term, which obeys normal distribution.

\subsection{Indicators}

Based on the existing research results and by considering data availability, agricultural human capital, farmer occupational differentiation, the extent of farmers' dependence on cultivated land, agricultural added value, agricultural machinery density, agricultural scale level and agricultural 
disaster rate were selected as the variables to study the factors influencing the GUECL in this paper (Table 2).

Table 2. Influencing factors of the GUECL.

\begin{tabular}{llc}
\hline \multicolumn{1}{c}{ Influencing Factors } & \multicolumn{1}{c}{ Representing Variables and Units } & Predictive Effect \\
\hline Agricultural human capital & $\begin{array}{l}\text { Proportion of population above high school education } \\
\text { level in the rural population aged six and above (\%) }\end{array}$ & Positive \\
\hline $\begin{array}{l}\text { Farmer occupational } \\
\text { differentiation }\end{array}$ & $\begin{array}{l}\text { Amount of agricultural employment/total rural } \\
\text { employment (\%) }\end{array}$ & Undefined \\
\hline $\begin{array}{l}\text { The extent of farmers' dependence } \\
\text { on cultivated land }\end{array}$ & $\begin{array}{l}\text { Rural household net farmland income per capita/rural } \\
\text { household net income per capita (\%) }\end{array}$ & Undefined \\
\hline Agricultural added value & Agricultural added value (ten thousand Yuan) & Undefined \\
\hline Agricultural machinery density & $\begin{array}{l}\text { Agricultural machinery gross power/agricultural crop } \\
\text { sown area (KW/hectare) }\end{array}$ & Undefined \\
\hline Degree of agricultural scale & Cultivated land area per capita (hectare/per capita) & Undefined \\
\hline Agricultural disaster rate & Crop disaster area/agricultural crop sown area (\%) & Negative \\
\hline
\end{tabular}

In the above influencing factors, (1) is an important condition that affects the GUECL-agricultural human capital, which is represented by the proportion of population above a high school education level in the rural population aged six and above in this paper. Generally, farmers with more education have a stronger learning ability for the GUECL and a deeper understanding of the concept of green environmental protection. Therefore, it was assumed that agricultural human capital has a positive effect on the GUECL. (2) The main characteristic of farmer differentiation is the occupational differences [41]. Considering data availability, the proportion of agricultural employment in total rural employment was adopted in this paper to represent the degree of farmer occupational differentiation [42]. The higher the proportion of agricultural employment in total rural employment is, the lower the degree of farmer occupational differentiation is. Farmer occupational differentiation results in differences in farmers' income levels and structures, so the influence of farmer occupational differentiation on the GUECL is undefined. (3) The higher the proportion of rural household per capita net farmland income in rural household per capita net income, the greater farmers' dependence on cultivated land income. On the one hand, they are motivated to apply more chemical fertilizers to ensure crop yield and maintain agricultural income; on the other hand, they are also motivated to protect soil fertility to obtain a long-term and stable farmland income. Therefore, the influence of farmers' dependence on cultivated land on the GUECL remains unknown. (4) According to the environmental Kuznets curve, agricultural added value may have different effects on the GUECL at different stages. Therefore, the influence remains undefined. (5) Agricultural machinery density reflects the level of agricultural mechanization. On the one hand, it is conducive for the efficient use of input factors and pollution reduction [43]; on the other hand, it may lead to an increase of non-expected output such as carbon emissions. Therefore, the influence of agricultural machinery density on the GUECL is unknown. (6) The scale effect brought by agricultural scale operation helps reduce the cost of fertilizer application, leading to the over application of fertilizers, but it helps improve cultivated land use efficiency [44]. Therefore, the influence of agricultural scale degree was undefined in this paper. (7) The higher the agricultural disaster rate is, the greater the factor input loss. Theoretically, the agricultural disaster rate has a negative effect on the GUECL.

\subsection{Analysis of Empirical Results}

In this paper, the software Stata 13.0 was used to conduct a random-effect panel Tobit regression analysis on the factors influencing the GUECL in the 30 provinces (autonomous regions or municipalities directly under the central government) of China during 2001-2016. The $p$ value of the model (Prob > chi2 $=0.000$ ) indicated that the model has passed the $1 \%$ significance level test. The log likelihood ratio $($ Log likelihood $=156.08984)$ indicated that the overall goodness of fit of the model was good with statistical significance. 
Table 3 shows that farmer occupational differentiation is not conducive to the improvement of the GUECL. The lower the proportion of agricultural employment in total rural employment is, the higher the degree of farmer occupational differentiation and the lower the GUECL. Farmer occupational differentiation is manifested in the following two aspects: The first is the change in farm households' income level and structure, and the second is the transfer of rural labor to nonagricultural industries. Farmer occupational differentiation helps increase farmers' non-agricultural income, thus alleviating farmers' financial constraints in purchasing chemical fertilizers. At the same time, farmer occupational differentiation increases the opportunity cost of farming. To save labor costs, farmers tend to reduce the frequency of fertilizer applications and increase the average fertilizer usage each time, resulting in the excessive use of chemical fertilizers. Additionally, farmer occupational differentiation strengthens farmers' ability to withstand risks, leading farmers to shift from planting grain crops to planting cash crops that produce higher yields but require more fertilizer.

Table 3. Tobit regression results of the GUECL influencing factors.

\begin{tabular}{lccc}
\hline \multicolumn{1}{c}{ Explanatory Variables } & Coef. & Std. Err. & $\mathbf{p ~}>|\mathbf{z}|$ \\
\hline Agricultural human capital & -0.01 & 0.08 & 0.861 \\
Farmer occupational differentiation & $0.50^{* * *}$ & 0.19 & 0.009 \\
The extent of farmers' dependence on cultivated land & $0.83^{* * *}$ & 0.18 & 0.000 \\
Agricultural added value & $3.11^{* * *}$ & 2.25 & 0.000 \\
Agricultural machinery density & $-6.89^{* *}$ & 3.10 & 0.026 \\
Degree of agricultural scale & 0.02 & 0.01 & 0.184 \\
Agricultural disaster rate & $-0.04 *$ & 0.02 & 0.063 \\
C & 0.42 & 0.09 & 0.000 \\
\hline rho & 0.77 & 0.05 & \\
\hline Wald chi2 (7) & 464.74 & & \\
Prob $>$ chi2 & 0.0000 & & \\
\hline
\end{tabular}

Note: ${ }^{*}, * *,{ }^{* * *}$ represent the significant levels of $10 \%, 5 \%$, and $1 \%$, respectively. If the sign of the coefficient is positive, the explanatory variable is positively correlated with the GUECL; if the sign of the coefficient is negative, the explanatory variable is negatively correlated with the GUECL.

The extent of farmers' dependence on cultivated land is positively related with the GUECL. The increase of the proportion of farmers' non-agricultural income reduces the adoption of environmentally friendly technologies such as formula fertilization by soil testing [45]. On the other hand, this provides conditions for rural labor force transfer, cultivated land scale management, and mechanized farming [46], increasing the undesirable outputs such as pesticide residuals and carbon emission while liberating labor force, thus negatively influencing the GUECL. Agricultural added value is significantly positive related with the GUECL. First, an increase in agricultural added value is conducive to an increase in desirable output; second, an increase in agricultural added value strengthens farmers' dependence on cultivated land, so they are more motivated to conserve soil fertility to ensure the long-term output from cultivated land, thus improving the GUECL.

Agricultural machinery density is significantly, negative related to the GUECL. The reason for this might be that the negative effect of agricultural mechanization on the GUECL is greater than the positive effect. The large-scale use of agricultural machinery not only aggravates resource consumption such as fossil fuels but also increases unexpected outputs such as carbon emissions. Furthermore, the large-scale use of agricultural machinery destroys primitive soil morphology, resulting in large-scale land loss through soil erosion or soil degradation, thereby aggravating the damage caused by agricultural non-point source pollution. With the deepening of agricultural mechanization, the challenges faced by rural agricultural resources and environmental systems are growing in regard to self-recovery, self-regulation, and the ability to resist disturbances. Rural agricultural resources and 
the environmental systems are increasingly close to their elastic limits ${ }^{4}$. China has reached a critical period in which its rural environmental carrying capacity has come increasingly close to the elastic limit of the resource system [47]. It is essential to properly control the scale and direction of agricultural mechanization and to develop new eco-friendly agricultural mechanization technologies.

The agricultural disaster rate is significantly negative related to the GUECL, which is consistent with our assumption. On the one hand, agricultural disasters can result in the loss of agricultural production inputs to some extent, thereby reducing desirable output. On the other hand, farm households that have suffered from natural disasters have a higher awareness of risk aversion, and they might tend to make up for the output loss resulting from natural hazards by increasing fertilizer application. In this study, agricultural human capital and the degree of agricultural scale did not pass the significance test, which may be related to the selection of indicators. The indicators need to be further improved in future research.

\section{Analysis of the Optimization of the GUECL}

Based on the SBM-VRS model, the slack values can be obtained. When the GUECL value is less than 1 , the value size of the slack variables can reflect the causes of the efficiency loss, providing a basis for its optimization. In this paper, the slack value of each input variable was divided by the corresponding input value to obtain the input redundancy rate in China from 2001 to 2016; the slack values of pollution and carbon emissions were divided by the corresponding pollution and carbon emissions, respectively, to obtain the redundancy rates of pollution and carbon emissions; the slack value of total agricultural output was divided by the corresponding total agricultural output value to obtain the insufficiency rate of the total agricultural output [48]. The calculation results are shown in Table 4.

Table 4 shows that redundancies existed in both input and undesirable output indicators to a different degree, and insufficiency rates of desirable output only slightly existed in 15 provinces. This result indicates that the main reason for the GUECL loss was the redundancy of inputs or undesirable outputs. The overconsumption of resources, excessive agricultural pollution, and carbon emissions were the main reasons for the low GUECL in China during 2001-2016.

From a national perspective, the input and output indicators with the highest redundancy rates are land input, pollution emissions, and mechanical input, ordered by their utilization of cultivated land in China. For 23 provinces, amounting to about 77\%, land input redundancy exists in varied degrees, and some provinces and cities with urgent land shortage such as Beijing and Guangdong are included. This indicates that the cultivated land resources in China have not been utilized at a high quality. This is consistent with the research conclusion of Pan and Ying (2013) [37]. Pollution emissions in the process of cultivated land utilization is the second key reason for efficiency loss, indicating that pesticide residuals, film residuals, and nitrogen and phosphorus loss from chemical fertilizer in Chinese agricultural production have become very serious. Agricultural film residuals lead to soil hardening, fertility decline, and crop yield reduction, and redundancies of chemical fertilizers and pesticides lead to ecological environment problems such as agricultural non-point source pollution, thus resulting in a decreased GUECL. The third key reason for efficiency loss is machinery input redundancy. In recent years, the implementation and improvement of the subsidy policy for agricultural machinery purchase in China has led to a sharp increase in agricultural machinery and equipment. However, limited by

4 The elasticity of the agricultural environmental system refers to the agricultural resource utilization system's ability to recover, self-regulate, and resist various pressures and disturbances. When internal or external disturbances or pressures upon the system have not exceeded its elastic limit (agricultural resources carrying capacity), the system can recover from the deviation and return to its original status. However, the elastic force is limited. When an external force is too powerful and exceeds the system's elastic limit, shifting the elastic force from its original equilibrium position, then the resource utilization system changes from one status to another because it is unable to restore to the original status. The higher the system elasticity is, the more room for human activities, the more opportunities for choice, the greater the resistance to natural disasters, etc. 
natural conditions such as topography and landform and influenced by social-economic conditions such as the Household Contract Responsibility System and the Land Equal Distribution System based on land quality in China, the cultivated land is fragmented, rough and uneven, resulting in the inefficient use of agricultural machinery.

Table 4. Optimized results of input and output of the GUECL.

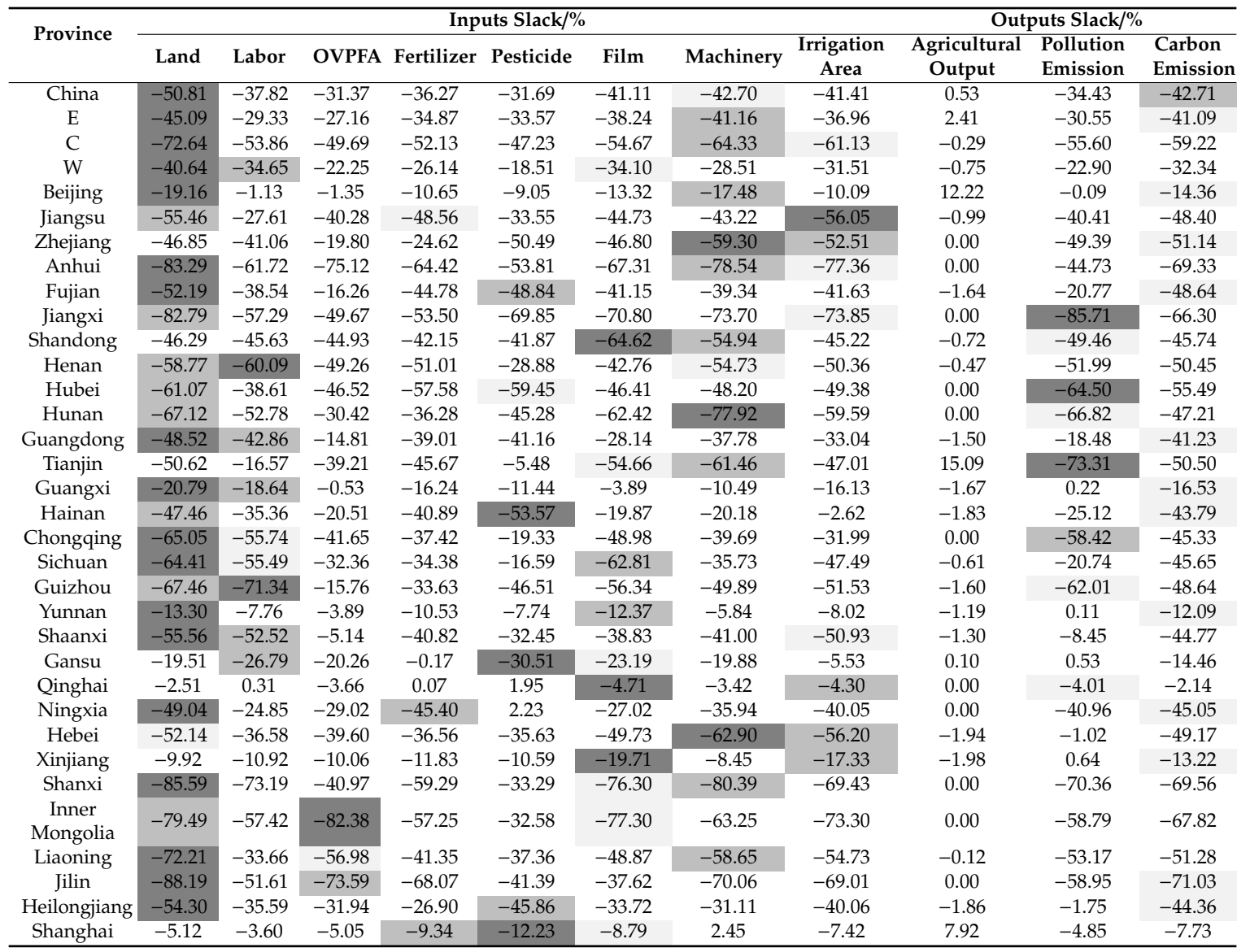

Note: Black represents the factor with the greatest optimization potential in a certain province. Dark gray represents the factor with the second greatest optimization potential, and light gray represents the factor with the third greatest optimization potential. E, C, and W are short for the eastern region, central region and western region, respectively.

From a regional perspective, in the eastern region, the main reasons for efficiency loss are land input redundancy, machinery input redundancy, and carbon emission redundancy; in the central region, the main reasons are land input redundancy, machinery input redundancy, and irrigation area redundancy; in the western region, the main reasons are land input redundancy, labor input redundancy, and agricultural film redundancy. In the process of cultivated land utilization, farmers in the eastern region tend to rely on high-intensity input in the short term to achieve a high output. Coupled with the unreasonable production process, simple and extensive disposal means for cultivated land waste, pollutions from cultivated land such as carbon emissions are increased [14]. Irrigation area redundancy exists in all three regions to varied degrees, especially in the middle region, Hebei and Jiangsu. Studies have shown that the annual wastage of water resources in Chinese agriculture is as high as 100 billion cubic meters [49]. In 2013, the effective utilization coefficient of agricultural irrigation water was only 0.523 in China, much lower than that of $0.7-0.8$ in developed countries. The grain output per cubic meter was less than $1.2 \mathrm{~kg}$, much lower than that of $2 \mathrm{~kg}$ in the developed countries [50]. At present, most of the cultivated land in China is dominated by flood irrigation, and the loss of water resource in some areas is as high as 60\%-80\% [51]. Many irrigation areas are in aging and disrepair, and the supporting facilities are not perfect, leading to low agricultural irrigation 
efficiency. Agricultural film redundancy exists in various regions of China, especially the central and western regions. In recent years, the covering area and application amount of agricultural film in China have increased rapidly, reaching $1.84 \times 10^{7} \mathrm{hm}^{2}$ in 2016 [52]. Considering the environmental risks of overusing agricultural film, the intensive and economical use of agricultural film is particularly important. Film-mulching and reusing should be encouraged to reduce the amount and residuals of agricultural film.

\section{Conclusions, Discussion and Policy Recommendation}

\subsection{Conclusions and Discussion}

From 2001 to 2016, the green use efficiency of cultivated land (GUECL) in China followed an upward trend with fluctuations. Room for resource conservation and pollution reduction exists in various provinces (autonomous regions or municipalities directly under the central government) to varied degrees. In the regional perspective, the eastern region has surpassed the western region and is ranked the first in the average GUECL among the three regions in China. The GUECL in the central region lags behind the eastern and western regions during the research period. In terms of the factors influencing the GUECL, farmer occupational differentiation, agricultural machinery density, and agricultural disaster rate are not conducive to the improvement of the GUECL, while agricultural added value and the extent of farmers' dependence on cultivated land are significantly, positively related to the GUECL. Through slack analysis, it was concluded that the GUECL in China can be optimized from aspects of land input, pollution emission and agricultural machinery input on the whole.

Some limitations still exist in this paper. Firstly, the unified emission pollution coefficient was adopted in the calculation of the undesirable output. However, cropping practices and farmers' planting preferences may affect the emission of undesirable outputs in different ways. Therefore, errors were inevitable due to the unified pollution emission coefficient. Secondly, in the analysis of the influencing factors, only the factors directly affecting the GUECL were taken into consideration, so the factors indirectly affecting the GUECL need to be further improved in future research.

\subsection{Policy Implications}

Measures to improve the GUECL can be taken from the following aspects. First, strengthen farmers' vocational skill training, vigorously cultivate new professional farmers, and expand the subjects of agricultural scale operation. Second, free the form of rural land transfer, improve the market for rural land transfer, and promote agricultural operation on a moderate scale. Third, promote green, ecological and sustainable agricultural production; develop traditional ecological agriculture; and produce green organic food. Fourth, strengthen the construction of water conservancy facilities and improve agricultural infrastructure. Fifth, establish a new agricultural technology extension system, and promote environmental-friendly technologies such as formula fertilization by soil testing and straw incorporation. Sixth, reasonably and appropriately introduce agricultural machinery and equipment. Develop and use agricultural machinery suitable for different topographic and geomorphologic conditions. Promote environmental-friendly agricultural machinery such as "fertilizer-saving" and "low carbon" machinery, as well as protective tilling machinery such as no-tillage farm machinery. Seventh, formulate targeted policies on residual film recovery and determine the standard for film remaining in cultivated land. Last, popularize agricultural insurance to promote farmers' ability to resist risks.

Author Contributions: Q.C. and H.X. conceptualized the research and performed the validation. Q.C. and H.X. administered the project, developed the methodology, curated the data, conducted the formal analysis, produced visualizations, and wrote and prepared the original draft manuscript. Q.C. and H.X. reviewed and edited the manuscript. Q.C. and H.X. acquired funding. Q.C. and H.X. contributed to drafting the manuscript and approved the final version of the manuscript. 
Funding: This study was supported by the National Natural Science Foundation of China (No. 41971243); the Academic and Technical Leaders Funding Program for Major Disciplines in Jiangxi Province (No. 20172BCB22011); the Fok Ying-Tung Fund(No. 141084); Jiangxi Postgraduate Innovation Project (No. YC2018-B069); 2019 Theoretical Research and Innovation Project of Young Marxists in Jiangxi Province (19QM25).

Acknowledgments: The authors would like to thank the reviewers and the editor whose suggestions greatly improved the manuscript.

Conflicts of Interest: The authors declare no conflict of interest.

\section{References}

1. Ye, H.; Pu, L.J. Study on Regional Difference and Convergence of Cultivated Land Utilization Efficiency in China. J. Nat. Resour. 2011, 2609, 1467-1474.

2. Luan, J.; Li, T.T.; Ma, K. Influence of Labor Transfer on Agricultural Non-point Source Pollution of Fertilizers in China. World Agric. 2016, 02, 63-69.

3. Behind the Ten Consecutive Increase of Grain Production in China: Groundwater Can Be Used as Fertilizer. Available online: http:/finance.sina.com.cn/china/20140314/234318514114.shtml?from=wap (accessed on 20 October 2019).

4. Huang, X.M.; Chen, C.Q.; Chen, M.Z.; Song, Z.W.; Deng, A.X.; Zhang, J.; Zheng, C.Y.; Zhang, W.J. Carbon footprints of major staple grain crops production in three provinces of Northeast China during 2004-2013. Chin. J. Appl. Ecol. 2016, 27, 3307-3315.

5. Yu, F.W. Xi Jinping's new thought of green development and agricultural green transformation development. China Rural Surv. 2016, 05, 2-9+94.

6. Kong, X. China must protect high-quality arable land. Nature 2014, 506, 7. [CrossRef] [PubMed]

7. Pawar, S.N.; Gatade, D.G. The total cropped area or gross area sown as percentage of net area sown gives a measure of land use efficiency which really means the intensity of cropping. Gold. Res. Thoughts 2013, 10, 115-120.

8. Xie, H.L.; Chen, Q.R.; Wang, W.; He, Y.F. Analyzing the green efficiency of arable land use in china. Technol. Forecast. Soc. Chang. 2018, 133, 15-28. [CrossRef]

9. Cui, X.; Zhang, Y.S. Analysis of China's agricultural environmental efficiency and environmental total factor productivity. Chin. Rural Econ. 2014, 8, 4-16.

10. Hu, Z.T.; Kong, D.S.; Jiao, J.S.; Jin, L.S. Ecological environment efficiency of grassland circulation-An empirical study based on Inner Mongolia and Gansu. Issues Agric. Econ. 2014, 3506, 90-97.

11. Li, Z.L.; Luo, X.F.; Xue, L.F.; Zhang, J.B. Analysis of the regional differentiation and influencing factors of agricultural green production efficiency in China. J. China Agric. Univ. 2017, 2210, 203-212.

12. Lu, X.H.; Kuang, B.; Li, J. Regional Differences and Influencing Factors of Cultivated Land Use Efficiency under the Constraint of Carbon Emission. J. Nat. Resour. 2018, 33, 657-668.

13. Catherine, B. The farmer as conservationist. Am. J. Altern. Agric. 2003, 18, 206-212.

14. Rahma, S.; Rahman, M. Impact of land fragmentation and resource ownership on productivity and efficiency: The case of rice producers in Bangladesh. Land Use Policy 2008, 26, 95-103. [CrossRef]

15. Oumarou, B.; Zhou, H.Q.; Rana, M.A. Analysis on technical efficiency of rice farms and its influencing factors in south-western of Niger. J. Northeast Agric. Univ. 2016, 23, 67-77.

16. Manjunatha, A.V.; Anikc, A.R.; Speelman, S. Impact of land fragmentation, farm size, land ownership and crop diversity on profit and efficiency of irrigated farms in India. Land Use Policy 2013, 31, 397-405. [CrossRef]

17. Alemdar, T.; Oren, M.N. Determinants of technical efficiency of wheat farming in south-eastern Anatolia Turkey: A nonparametric technical efficiency analysis. J. Appl. Sci. 2006, 6, 827-830.

18. Khai, H.V.; Yabe, M. Technical efficiency analysis of rice production in Vietnam. J. ISSAAS 2011, 17, $135-146$.

19. Naceur, M.; Mongi, S. The technical efficiency of collective irrigation schemes in south-eastern of Tunisia. Int. J. Sustain. Dev. World Policy 2013, 2, 87-103.

20. Souza, G.; Gomes, E.G. Improving agricultural economic efficiency in Brazil. Int. Trans. Oper. Res. 2015, 22, 329-337. [CrossRef]

21. Kang, P. Comparative Analysis of Parametric Method and Nonparametric Method in Economic Efficiency Research. Econ. Forum 2005, 19, 139-140. 
22. Fukuyama, H.; Weber, W.L. A directional slacks-based measure of technical inefficiency. Socio-Econ. Plan. Sci. 2009, 43, 274-287. [CrossRef]

23. Chung, Y.H.; Färe, R.; Grosskopf, S. Productivity and undesirable outputs: A directional distance function approach. J. Environ. Manag. 1997, 51, 229-240. [CrossRef]

24. Fukuyama, H.; Weber, W.L. A slacks-based inefficiency measure for a two-stage system with bad outputs. Omega 2010, 38, 398-409. [CrossRef]

25. Fukuyama, H.; Yoshida, Y.; Managi, S. Modal choice between air and rail: A social efficiency benchmarking analysis that considers $\mathrm{CO}_{2}$ emissions. Environ. Econ. Policy Stud. 2011, 13, 89-102. [CrossRef]

26. Färe, R.; Grosskopf, S. Directional distance functions and slacks-based measures of efficiency. Eur. J. Oper. Res. 2010, 200, 320-322. [CrossRef]

27. Mahlberg, B.; Sahoo, B.K. Radial and non-radial decompositions of Luenberger productivity indicator with an illustrative application. Int. J. Prod. Econ. 2011, 131, 721-726. [CrossRef]

28. Barros, C.P.; Managi, S.; Matousek, R. The technical efficiency of the Japanese banks: Non-radial directional performance measurement with undesirable output. Omega 2012, 40, 1-8. [CrossRef]

29. Gong, D.P.; Zhao, T.; Ci, Z.C.; Yao, H. Assessment of China's interprovincial industrial fossil energy efficiency based on super-efficiency SBM and analysis of the influencing factors. Acta Sci. Circumstantiae 2015, 3502, 585-595.

30. Tone, K. A slacks-based measure of super-efficiency in data envelopment analysis. Eur. J. Oper. Res. 2002, 143, 32-41. [CrossRef]

31. Coelli, T.J.; Rao, D.S.P.; O’Donnell, C.J.; Battese, G.E. An Introduction to Efficiency and Productivity Analysis; Kluwer Academic Publishers: Boston, MA, USA, 2006.

32. Chiu, Y.; Huang, C.W.; Chung, C.T. Measuring the repair performance for stricken cultivated land and agricultural efficiency in China with a modified two-stage DEA model. Asia-Pac. J. Oper. Res. 2011, 5, 633-649. [CrossRef]

33. Feng, Y.G.; Peng, Y.; Deng, Z.B.; Wang, J. Spatial-temporal Variation of Cultivated Land's Utilization Efficiency in China Based on the Dual Perspective of Non-point Source Pollution and Carbon Emission. China Popul. Resour. Environ. 2015, 25, 18-25.

34. Kang, X.H. Analysis of Pesticide Residues in Soil in Mianyang Tea Garden. China Plant Prot. 2006, 12, 38-40.

35. Cheng, Z.H.; Liu, S.P.; Sun, Z.C.; Sun, C.Y.; Han, T.H.; Men, S.Y.; Zhang, W.X.; Zhao, B.F. Investigation on Agricultural Film Residues and Analysis of Its Influencing Factors in Tianjin. J. Agric. Resour. Environ. 2011, 28, 90-94.

36. Lai, S.Y.; Du, P.F.; Chen, J.N. Evaluation of Non-point Source Pollution based on Unit Analysis. J. Tsinghua Univ. (Sci. Technol.) 2004, 09, 1184-1187.

37. Tu, Z.G. Coordination of environment, resources and industrial growth. Econ. Res. J. 2008, 02, $93-105$.

38. Tobin, J. Estimation of Relationships for Limited Dependent Variables. Econometrica 1958, 26, 24-36. [CrossRef]

39. Xu, H.Z.; Guo, Y.Y.; Wu, G.C. Influence of farmer differentiation on cultivated land utilization efficiency-Empirical analysis based on household survey data. Chin. Rural Econ. 2012, 06, 31-39+47.

40. Chen, Q. Advanced Econometrics and the Application of Stata, 2nd ed.; Higher Education Press: Beijing, China, 2014.

41. Xu, H.Z.; Guo, Z.X.; Guo, Y.Y. Farmer occupational differentiation, old-age security and rural land transfer-An empirical study based on 372 questionnaires from farmers in Nanjing City. J. Agrotech. 2011, 01, 80-85.

42. Li, Y.B.; Wang, W.X.; Peng, J.Q. Research on the relationship between farmer occupational differentiation and urbanization-From theoretical and empirical perspectives. World Agric. 2013, 08, 50-53.

43. He, Y.Q.; Dai, X.W. Analysis of the spatial-temporal characteristics of the drivers of China's agricultural carbon emission. Resour. Sci. 2016, 3809, 1780-1790.

44. Xu, Q.; Lei, G.P.; Yang, H.X. Study on Spatial-temporal Differences and Influencing Factors of Cultivated Land Use Efficiency in Heilongjiang Province. Chin. J. Agric. Resour. Reg. Plan. 2017, 38, 33-40.

45. Wang, S.Q.; Chen, M.Q.; Peng, X.X.; Liu, T.J. Empirical Study on the Impact of Farmer Differentiation on the Adoption of Environmentally Friendly Technology: Based on the Investigation of 554 Farmers on the Application of Soil Testing and Formulated Fertilization Technology. J. China Agric. Univ. 2018, 23, 187-196. 
46. Cao, Y.; Hu, J.L. Agricultural Mechanization under the Household Land Contract System in China: Based on the Survey Data of 17 Provinces (Regions and Cities) in China. Chin. Rural Econ. 2010, 10, 57-65.

47. Liu, Y.Q.; Huang, Y. Empirical Study on the Impact of Agricultural Mechanization on Rural Environment. J. Agric. Mech. Res. 2016, 38, 75-80.

48. Pan, D.; Ying, R.Y. Agricultural Eco-efficiency Evaluation in China based on SBM model. Acta Ecol. Sin. 2013, 33, 3837-3845. [CrossRef]

49. Liu, Q.; Wu, Z.T. Problems and Countermeasures of Sustainable Utilization of Agricultural Water Resources in China. China South. Agric. Mach. 2017, 48, 92.

50. Li, P.H. Analysis on Problems and Countermeasures of Agricultural Water Resources Utilization in China. Rural Econ. Sci-Technol. 2016, 27, 39-40.

51. Xing, Y. Discussion on the Fundamental Way of Agricultural Environmental Protection. Nong Min Zhi Fu Zhi You 2014, 11, 160.

52. Xu, Y.M.; Fang, S.J.; Ma, X.P.; Zhu, Q.Q. Study on Strategies to Prevent and Control Agricultural Mulch Pollution. Eng. Sci. 2018, 20, 96-102.

(C) 2019 by the authors. Licensee MDPI, Basel, Switzerland. This article is an open access article distributed under the terms and conditions of the Creative Commons Attribution (CC BY) license (http://creativecommons.org/licenses/by/4.0/). 